\title{
A Lower Bound on Real Interest Rates
}

\author{
Jesse Aaron Zinn \\ Clayton State University
}

October 9, 2016

\begin{abstract}
I show that real interest rates can be no lower than $-100 \%$. This contrasts with recent commentary suggesting that there is no lower bound on the natural rate of interest. I discuss how using the textbook approximation to the Fisher equation can lead to the erroneous belief that there is no lower bound on real interest rates, so this analysis serves as a reminder to avoid using this approximation when considering the effects of extreme levels of inflation.

JEL CODES: E43, E52

Keywords: Real Interest Rates, Monetary Policy, Lower Bounds
\end{abstract}

\section{Introduction}

Negative real interest rates have been the norm in the United States and other countries since the financial crisis of 2007-8. Much worse, Japan has often had negative real interest rates going back to the early 1990s. In some countries, such as Denmark and Switzerland, even nominal interest rates have turned negative, disproving the idea that zero is an effective lower bound. These phenomena have, no doubt, lead many to wonder how low rates can go. 
The purpose of this note is to highlight the existence of a lower bound on real rates of interest. Specifically, I show that a real interest rate can be no lower than $-100 \%$. This is an immediate consequence of the fact that an investment project cannot lose more than what was put into it, ${ }^{1}$ which I show formally in the next section. Seeing as negative real rates are a characteristic of both liquidity traps (Krugman, 1998; Eggertsson and Krugman, 2012) and secular stagnation (Summers, 2014, 2015), a lower bound on real interest rates suggests there is a limit to the severity of at least one dimension of these maladies.

The existence of a lower bound on real interest rates contradicts recent comments at the 40th Annual Central Banking Seminar, sponsored by the Federal Reserve Bank of New York, where it was said, "nothing dictates that the natural rate of interest should be positive; indeed, the natural rate has no effective lower bound." ${ }^{2}$ The natural rate is the real rate of interest for which output is at potential and inflation is constant. ${ }^{3}$ Given the context, it is clear that the remark in question was an afterthought, unnecessary to the main point that the natural rate is not necessarily positive. ${ }^{4}$ In light of this, I find the error to be excusable. Nonetheless, it is the case, as I show, that a lower bound exists for all real interest rates, including the natural rate.

\footnotetext{
${ }^{1}$ For this to be true, what was put into an investment must include any debt used in its financing. There is no lower bound on an individual's personal losses on short sells or with leverage getting arbitrarily close to $100 \%$.

${ }^{2}$ The italics were added to emphasize the exact passage that is in contention. The remarks can be found in Fischer (2016).

${ }^{3}$ Holston, Laubach, and Williams (2016) provides recent estimates of the natural rate for United States, Canada, the Euro Area, and the United Kingdom, finding declines in this variable in all four economies over the last few decades.

${ }^{4}$ Leading economists have found it necessary to make this point again and again over the better part of a century. See, for example, Keynes (1936) and Samuelson (1958).
} 


\section{The Lower Bound}

Consider any asset with a nominal rate of return of $i \geq-1$. Restricting the nominal rate to be no less than -1 limits the classes of assets to those where the investment cannot result in a loss greater than what is put in. This is the case for investments considered in the vast majority of macroeconomic studies. Examples of such investments include spending on physical capital, inventories, and R\&D, as well as holding currency, lending money, and buying bonds.

Let $\pi$ represent the rate of inflation over the period it takes for the asset to pay off. ${ }^{5}$ The real rate of interest $r$ on the asset is determined by the Fisher equation:

$$
1+r=\frac{1+i}{1+\pi}
$$

Solving for the real interest rate yields

$$
r=\frac{i-\pi}{1+\pi}
$$

The fact that -1 is a lower bound for $r$ follows directly from the assumption that $i \geq-1$. Subtract $\pi$ and divide the resulting differences by $1+\pi$ on both sides of the inequality to find that

$$
i \geq-1 \quad \Longrightarrow \quad r \geq-1
$$

for any value of $\pi .^{6}$

There are two ways $r$ could approach its lower bound, and they are logically

\footnotetext{
${ }^{5}$ All results in this work hold for cases in which there is uncertainty about inflation. So, for example, $\pi$ could represent expected inflation.

${ }^{6}$ The converse is also true: $r \geq-1$ implies $i \geq-1$, so if one knows that the real rate of return on some asset is no less than -1 then the nominal rate must also be no less than -1 .
} 
consistent with each other in the sense that one does not preclude the other. ${ }^{7}$ First, regardless of the level of inflation, $r$ is decreasing in $i$, and if $i$ reaches its minimum value of -1 then $r=-1$ as well.

The second way that $r$ can approach the lower bound of -1 is through increases in the rate of inflation. Episodes of hyperinflation corroborate the notion that for any value of $\pi$ there is no apparent reason $\pi$ cannot be one percentage point higher. Therefore, it seems reasonable to consider what happens to $r$ as $\pi$ increases without bound. Taking the limit, we find that $r$ goes to -1 from above as $\pi$ goes to $\infty$, for any $i$.

\section{Concluding Remarks}

In practice, many economists think of real interest rates using the approximation to the Fisher equation $r \approx i-\pi$. Indeed, many introductory textbooks teach students that $r=i-\pi$ without warning that this is not generally accurate. If one takes the approximation as precise then it is natural to arrive at the conclusion that $r$ has no lower bound, since $i-\pi$ goes to $-\infty$ as $\pi$ goes to $\infty$. We can avoid such errors by remembering that $i-\pi$ is only a good approximation when $\pi$ is near zero and that $i-\pi$ becomes an increasingly worse approximation as $\pi$ moves away from zero in either direction.

\footnotetext{
${ }^{7}$ In other words, they are not mutually exclusive.
} 


\section{References}

Eggertsson, G. B., and P. Krugman (2012): "Debt, Deleveraging, and the Liquidity Trap: A Fisher-Minsky-Koo Approach," The Quarterly Journal of Economics, 127(3), 1469-1513.

Fischer, S. (2016): "Low Interest Rates," Remarks at 40th Annual Central Banking Seminar, sponsored by the Federal Reserve Bank of New York [Accessed: 201610 06].

Holston, K., T. Laubach, and J. Williams (2016): "Measuring the Natural Rate of Interest: International Trends and Determinants," in NBER International Seminar on Macroeconomics 2016. Journal of International Economics.

Keynes, J. M. (1936): The General Theory of Employment, Interest, and Money. MacMillon, New York.

Krugman, P. R. (1998): “It's Baaack: Japan's Slump and the Return of the Liquidity Trap," Brookings Papers on Economic Activity, (2), 137-205.

Samuelson, P. A. (1958): "An Exact Consumption-Loan Model of Interest With or Without the Social Contrivance of Money," The Journal of Political Economy, 66(6), 467-482.

Summers, L. H. (2014): "US Economic Prospects: Secular Stagnation, Hysteresis, and the Zero Lower Bound," Business Economics, 49(2), 65-73.

(2015): "Demand Side Secular Stagnation," The American Economic Review, 105(5), 60-65. 